\section{"Rebeldia e desalento": Um estudo comparativo dos enquadramentos sobre o Congresso Nacional em editoriais de Folha de S. Paulo e de $O$ Estado de S. Paulo}

["Rebellion and discouragement": A comparative study of the frameworks on the National Congress in Folha de S. Paulo and $O$ Estado de S. Paulo editorials]

\author{
Camila Mont'Alverne \\ Universidade Federal do Paraná \\ [Federal University of Paraná]
}

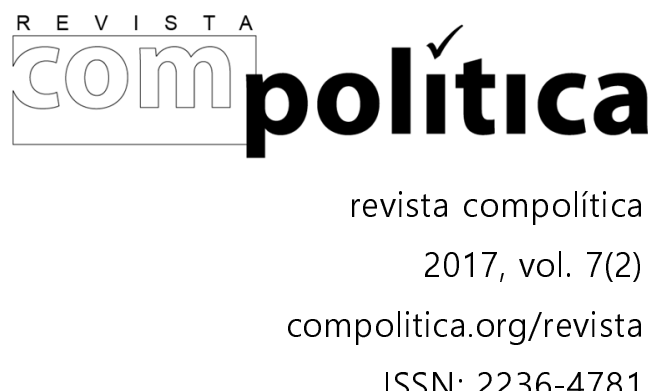

DOI: 10.21878/compolitica.2017.7.2.319 () Open Access Journal

\begin{abstract}
Resumo
O objetivo do artigo é apresentar, comparar e discutir os enquadramentos mobilizados pelos editoriais dos jornais Folha de S. Paulo e O Estado de S. Paulo ao tratar do Congresso Nacional. Por meio de uma Análise de Enquadramentos, o trabalho identifica que os jornais coincidem em quais frames acionam mais frequentemente: "Relações conflituosas entre governo e base aliada e entre governo e Congresso de forma geral" e "Providências necessárias para a economia brasileira e medidas que devem ser tomadas". Foram encontradas diferenças entre os outros enquadramentos mobilizados, indicando as preferências de cada um dos periódicos. Os editoriais tendem a focar nas disputas políticas e apresentar os agentes políticos como desprovidos de preocupação com o interesse público, mas também há espaço para discussão de questões substantivas, que ultrapassem o jogo político.
\end{abstract}

Palavras-chave: Enquadramento, Congresso Nacional, Editorial.

\begin{abstract}
The article aims to present, to compare and to discuss frames mobilized by editorials of two Brazilian newspapers, Folha de S. Paulo and O Estado de S. Paulo, when they are referring to Brazilian Congress. Using Frame Analysis, we identify that the publications activate two frames more frequently: "Conflicts between government and its allies in Congress and between government and Congress in general"; "Measures that should be taken to improve Brazilian economy". We found differences among the other frames the newspapers mobilized, what indicates that their priorities sometimes differ. The editorials tend to focus on political contests and to present political agents with no concerns towards public interests, but there is also discussion pertinent to substantial issues.
\end{abstract}

Keywords: Framing; Brazilian Congress; Editorial. 


\section{"Rebeldia e desalento": Um estudo comparativo dos enquadramentos sobre o Congresso Nacional em editoriais de Folha de S. Paulo e de O Estado de S. Paulo}

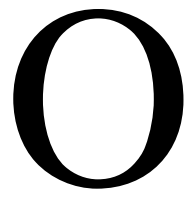

Jornalismo dispõe da possibilidade de oferecer aos cidadãos uma forma de compreender o mundo, especialmente, no que se refere a instituições às quais eles não têm acesso cotidianamente - a não ser, através dos media. Sua influência se dá não apenas junto ao público que o consome, mas chega a outros campos sociais, na medida em que a cobertura pode visibilizar alguns assuntos e perspectivas, favorecendo agentes específicos.

As empresas de comunicação exercem uma função representativa nas sociedades contemporâneas, constituindo-se como um espaço privilegiado para disseminação de perspectivas diversas e dos projetos dos grupos em conflito na sociedade (MIGUEL, 2014). A cobertura jornalística contribui, assim, para reforçar determinadas perspectivas e estabelecer as prioridades, em detrimento de outras concepções, que não terão a mesma possibilidade de adentrar a esfera de visibilidade pública.

Deste modo, é inegável que a percepção da atuação de instituições como a Câmara dos Deputados ou o Senado Federal está ligada à sua cobertura jornalística, pois, dessa forma, é visibilizado tanto o que ocorre no interior de tais instituições como o que seus integrantes fazem fora delas (ARNOLD, 2004; COOK, 1989; JORGE, 2003). Em certa medida, os próprios níveis de confiança nas instituições são influenciados pela visibilidade oferecida a eles pela comunicação de massa - e, no caso brasileiro, o Congresso figura entre aquelas das quais os cidadãos mais desconfiam ${ }^{1}$.

Por outro lado, as empresas jornalísticas são instituições dotadas de interesses próprios, e eles podem influenciar o teor da cobertura. Os editoriais, por seu caráter institucional, são

\footnotetext{
${ }^{1}$ Disponível <http://www1.folha.uol.com.br/colunas/monicabergamo/2016/10/1827041-planalto-so-tem-prestigiomaior-que-congresso-e-partidos-mostra-pesquisa.shtml>. Acesso em 2 jul 2017.
} 
textos nos quais o jornal apresenta suas ideias, expondo-se junto à sociedade, ao mesmo tempo em que precisam resguardar a legitimidade de representantes do interesse público.

Partindo desta problemática, o artigo tem como objetivo apresentar, comparar e discutir um mapeamento dos enquadramentos mobilizados pelos editoriais dos jornais Folha de $\mathrm{S}$. Paulo e O Estado de S. Paulo ao tratar do Congresso Nacional. Isso permite perceber como dois quality-papers tratam instituições de grande importância para a democracia do país, bem como quais são as prioridades das empresas quando se dirigem a tais instituições.

O texto está organizado da seguinte forma: na próxima seção, discute-se o papel do campo jornalístico nas democracias e a função dos editoriais. Depois, são esmiuçadas as estratégias metodológicas. No tópico seguinte, apresenta-se a análise. Por fim, são realizadas a discussão e as considerações finais do artigo.

\section{O papel do campo jornalístico: para além da mediação entre sociedade e agentes políticos}

Já se sabe que o papel do Jornalismo nas democracias vai além da mediação entre a esfera civil e os agentes políticos. A percepção da atuação de diversas instituições, como Câmara e Senado, bem como a de seus integrantes, está ligada à cobertura, por ser esta uma das principais formas pela qual é visibilizado o que ocorre no interior delas. As empresas de comunicação, por sua vez, são instituições dotadas de interesses próprios, os quais podem ser conflitantes com os dos agentes políticos. Ao constituir-se como um dos principais players a controlar o acesso à esfera de visibilidade pública, o Jornalismo faz com que os atores políticos se adequem às suas rotinas e regras, caso queiram ser visibilizados.

Assim, os agentes políticos são obrigados a dialogar com a lógica própria do Jornalismo para ganhar visibilidade ou para colocar agendas em pauta (AZEVEDO; CHAIA, 2008; CHAIA, 1999; COOK, 2005; GOMES, 2004). A relação entre campo político e midiático não é opcional, tendo em vista que os agentes de um campo possuem recursos que interessam aos atores do outro, fazendo com que o relacionamento entre eles seja permeado por tensões (GOMES, 2004; STRÖMBÄCK; NORD, 2006; VAN AELST et al., 2008). 
A necessidade de obter visibilidade tem impacto sobre a disputa pelo poder. No caso do Legislativo, por exemplo, a disputa por cargos passa a acontecer não somente em função do poder político, mas também pela possibilidade de ser visibilizado e emplacar agendas. A relação com a Comunicação, portanto, passa a ser parte do jogo político, não podendo ser considerada um detalhe ou um adendo às estratégias legislativas (COOK, 1989) - pelo menos, quando se trata de agentes políticos com projeção nacional (ou com planos de alcançá-la).

Não obstante a importância das relações com o campo político, as características da cobertura jornalística são frequentemente problematizadas pela literatura. Critica-se o foco nos conflitos entre os diversos agentes, posicionando-os, necessariamente, em lados antagônicos; a ênfase a suas intenções, em vez de considerar os resultados das ações; o foco no jogo político e não em questões substanciais; o cinismo e desconfiança dos jornalistas que lidam com os agentes políticos; e a simplificação excessiva de assuntos complexos (AALBERG; STRÖMBÄCK; DE VREESE, 2012; ARNOLD, 2004; CAPELLA; JAMIESON, 1997; COOK, 1989, 2005; EDELMAN, 1988; ERIKSSON; OSTMAN, 2013; FALASCA, 2014; FALLOWS, 1997; KOVACH; ROSENSTIEL, 2004; KUMAR, 2007; MIGUEL, 2002; MOTTA; GUAZINA, 2011; NOVELLI, 2010; RODRIGUES, 1997; SCHUDSON, 2008). Ao mesmo tempo, deve-se considerar que a cobertura crítica direcionada aos agentes políticos pode fortalecer a prestação de contas, mecanismos de transparência ou constrangê-los a comportar-se de forma que preserve sua relação com a sociedade.

\footnotetext{
O que o jornalismo garante para a esfera civil é um fluxo alternativo de comunicação política, fora do controle dos interesses do campo político, portanto, aparentemente mais confiável e mais respeitoso do interesse civil, do interesse público (GOMES, 2009, p. 78).
}

Especificamente no que concerne a abordagem sobre as atividades do Congresso Nacional pelo Jornalismo, pesquisas sobre o assunto, como as de Azevedo (2005), Azevedo e Chaia (2006) e Jorge (2003), apontam que os media priorizam tratar das relações com o Executivo, mesmo em textos dedicados a abordar o Legislativo. Novelli (2010) diagnostica 
personalização no material jornalístico sobre o Congresso, que seria focado na atuação de alguns parlamentares em vez de tratar da instituição de maneira geral, enquanto trabalhos presentes no livro de Aldighirni (2015) sustentam que a cobertura não aborda medidas positivas encampadas pelo Congresso. Já em seu estudo, Rodrigues (2011) aponta que há mais cobertura negativa para o Legislativo em relação ao Executivo, com manutenção de tal padrão ao longo do tempo.

Fica claro, pelos trabalhos elencados e pelas características do Jornalismo político discutidas anteriormente, que a ênfase da cobertura sobre Congresso Nacional - e do campo político, de maneira geral - tende a recair sobre as disputas entre os diferentes agentes envolvidos, deixando em segundo plano questões substanciais, com predominância de visibilidade negativa para a instituição e seus integrantes. A diferença é que boa parte destas pesquisas se debruçou sobre o material informativo dos periódicos, enquanto este artigo trata de um gênero particular dentro da seção opinativa.

\section{O editorial: um gênero jornalístico singular}

A página opinativa, de maneira geral, pode ser considerada a alma do jornal, por ser o espaço no qual se encontram seus valores, ideais e posições diante das questões que se apresentam à sociedade (AZEVEDO, 2016). Localizado dentro da seção opinativa, o editorial é um texto que cumpre função ímpar em um periódico, pois é nele, especificamente, que a publicação apresenta seus posicionamentos para a sociedade (ARMAÑANZAS; NOCÍ, 1996; BELTRÃO, 1980; GRADIM, 2000; RUPAR, 2007).

A função do editorial, porém, não é limitada a oferecer à sociedade uma interpretação sobre os acontecimentos. Hallock (2007) defende que o editorial tem uma função transcendente à de apresentar a opinião do periódico, colocando em domínio público, para consumo e discussão, assuntos, eventos e ideias. Já Kahn e Kenney (2002) argumentam que o texto procura pautar o debate público, algo também apontado por Azevedo (2016), ao tratar do caso brasileiro. Jornais de prestígio, portanto, ocupam a função de gatekeepers e estabelecedores da agenda (BILLEAUDEAUX et al., 2003), tendo em mente, como 
público-alvo de seus editoriais, as elites políticas e econômicas (ALBRIGHT, 1995; HALLOCK, 2007; IZADI; SAGHAYE-BIRIA, 2007; MELO, 1985).

Outro papel transcendente ao de orientar o leitor é a função político-mercadológica desempenhada pelos editoriais. Por um lado, o texto carregando a opinião institucional da empresa diferencia os periódicos entre si (MARQUES; MONT'ALVERNE; MITOZO, 2017), na medida que o leitor consegue ter uma ideia de quais são seus compromissos e prioridades. O editorial constitui-se, assim, como um texto no qual o periódico constrói sua própria imagem perante a audiência. Diante de um material informativo que tende a ser semelhante em todas as publicações, é um espaço para a empresa delimitar sua identidade junto ao público.

Já o papel político dos editoriais se desenrola a partir da liberdade, garantida pelas características do gênero, para os media expressarem publicamente sua opinião, fazendo uso do direito de se apresentarem como atores autônomos (EILDERS, 1999). Deste modo, o editorial é o espaço no qual o periódico apresenta-se claramente como agente dotado de interesses e demandas, criando um paradoxo para sua atuação.

No caso do editorial, a publicação tem de assumir seu caráter de construtor da realidade, pois não pode justificar o conteúdo do material com estratégias como a objetividade (MONT'ALVERNE; MARQUES, 2015), o que pode trazer riscos à credibilidade e à imagem cultivada pelas empresas. Neste sentido, nem sempre é de se esperar uma cobertura mais amena nos editoriais em relação ao que acontece no conteúdo informativo. Em muitos momentos, ele é o espaço ideal para concretizar as cobranças, até porque o periódico dispõe do artifício de apresentar soluções aos problemas detectados, algo que não pode fazer diretamente, pelo menos - na seção informativa. Assim, apesar de ter rotinas e características distintas da cobertura noticiosa, o editorial pode manter o padrão deste tipo de cobertura, aprofundando críticas e cobranças ao campo político e contribuindo para legitimar o Jornalismo como representante do leitor. 


\section{Metodologia}

A pesquisa se debruça sobre editoriais dos jornais $O$ Estado de S. Paulo (OESP) e Folha de S. Paulo (FSP), dois quality papers brasileiros. A escolha por trabalhar com esse tipo de jornal leva em conta a credibilidade e ressonância que dispõem junto às elites políticas e econômicas, como é exemplificado pelo fato de OESP e FSP estarem entre os periódicos preferidos dos deputados federais ${ }^{2}$.

O corpus da investigação é formado por 164 editoriais publicados, sendo 124 por OESP e 40 pela FSP, ao longo de seis meses entre 2011 e 2013, período que faz parte da Legislatura 2011-2015. Desconsiderou-se trabalhar com o ano de 2014 por ser ano eleitoral, no qual a cobertura tende a ser diferenciada. Pela impossibilidade de trabalhar com todos os editoriais publicados no período, foi construído um semestre artificial. A estratégia possibilita que a pesquisa alcance um período de tempo mais extenso, tornando-a mais representativa, além de conferir maior aleatoriedade ao corpus. Assim, foram coletados editoriais de janeiro e fevereiro de 2011, março e abril de 2012 e maio e junho de 2013. Ademais, só foram considerados textos que mencionassem uma das três palavras-chave escolhidas para a pesquisa, a saber: "Congresso", "Câmara" ou "Senado"3. Os editoriais coletados foram publicados no seguinte intervalo:

Tabela 1 - Datas nas quais os editoriais que compõem o corpus foram publicados

01/01/2011 a $28 / 02 / 2011$

$01 / 03 / 2012$ a $30 / 04 / 2012$

$01 / 05 / 2013$ a $30 / 06 / 2013$

Fonte: Elaboração da autora (2017).

\footnotetext{
${ }^{2}$ Disponível em <http://www.institutofsbpesquisa.com.br/pdf/midia-e-politica-2016.pdf>. Acesso em 29 jun. 2017.

${ }^{3}$ Só compõem o corpus, porém, editoriais que se mencionam o Congresso Nacional, a Câmara dos Deputados ou o Senado Federal, já que não há interesse em analisar outros tipos de congresso ou de casas legislativas.
} 
A quantidade de editoriais analisada não é a mesma em cada jornal, até porque FSP publica menos editoriais que OESP. A divisão dos editoriais por data e por jornal está detalhada abaixo ${ }^{4}$ :

Tabela 2 - Divisão dos editoriais por data e jornal

\begin{tabular}{l|l|l|l}
\hline Período & $\begin{array}{l}\text { O Estado de S. } \\
\text { Paulo }\end{array}$ & Folha de S. Paulo & Total \\
\hline $\begin{array}{l}\text { Janeiro e fevereiro de } \\
2011\end{array}$ & 31 & 6 & 37 \\
\hline Março e abril de 2012 & 50 & 24 & 74 \\
\hline Maio e junho de 2013 & 43 & 10 & 53 \\
\hline Total & 124 & 40 & 164 \\
\hline
\end{tabular}

Fonte: Elaboração da autora (2017)

Definido o corpus, procedeu-se à exploração dos textos. O trabalho lança mão de uma Análise de Enquadramentos para examinar as peças. O procedimento é baseado nas estratégias apresentadas por Matthes e Kohring (2008) e adaptadas por Vimieiro (2010). Considera-se que a análise dos enquadramentos pode oferecer uma forma relevante para aferir os resultados aos quais a pesquisa procura chegar, sendo os editoriais privilegiados para a tarefa. Neste sentido, Essary (2007, p. 513) defende que os editoriais são a forma ideal de comunicação para análise de enquadramento por: a) serem peças de escrita assertivas, nas quais o objetivo do autor é assumido como o de persuadir os leitores, enquadrando o assunto examinado; b) sua escrita é estratégica, minimizando dúvidas acerca do intuito do conteúdo expressado.

Devido às dificuldades de identificar o frame de cada texto e o risco de que a classificação fique excessivamente atrelada à subjetividade da pesquisadora, são identificados os elementos que compõem o enquadramento e, em seguida, eles são agrupados de acordo com suas semelhanças e diferenças. $\mathrm{O}$ agrupamento de tais elementos constitui o frame.

Para delimitar os elementos que compõem os frames, recorre-se ao conceito de enquadramento de Entman (1993, p. 52, grifo do autor). Para o pesquisador, "Enquadrar é selecionar alguns aspectos de uma realidade percebida e fazê-los mais salientes em um

\footnotetext{
${ }^{4}$ A lista completa de editoriais analisados está disponível na dissertação (MONT’ALVERNE, 2016).
} 
texto, de modo a promover uma definição particular do problema, uma interpretação causal, uma avaliação moral e/ou uma recomendação de tratamento para o item descrito". Assim, Matthes e Kohring (2008) identificam quatro elementos que compõem um frame: 1) a definição de um problema: consiste em uma questão ou atores relevantes que discutem o problema; 2) uma interpretação causal: a atribuição de falha ou sucesso concernente a resultados específicos; 3) uma avaliação moral: a avaliação pode ser positiva, negativa ou neutra e referir-se a diferentes objetos ${ }^{5}$; e 4) a recomendação de uma solução para o problema: uma chamada contra ou a favor de uma certa ação para resolver o problema. Após a identificação dos elementos nos textos, eles serão agrupados, procurando criar grupos com poucas diferenças entre si e com diferenças significativas para os outros.

Antes da classificação dos enquadramentos, foi realizada uma análise de clusters por similaridade léxica, de caráter exploratório, a fim de identificar os grupos que mantêm semelhanças entre si. A análise foi realizada utilizando o software de análise de conteúdo NVivo, usando o coeficiente de Sørensen como métrica de similaridade. O NVivo também foi utilizado para a identificação e codificação dos elementos dos frames. Grande parte dos elementos encontrados são trechos dos próprios editoriais, a fim de distorcer ao mínimo o conteúdo dos editoriais quando a análise foi realizada. Reconhece-se, porém, a impossibilidade de oferecer uma análise completamente objetiva, inclusive porque o processo de codificação envolve escolhas que dependem do pesquisador ${ }^{6}$.

\section{Análise}

A fim de possibilitar explorar os enquadramentos mapeados pelo trabalho, serão apresentados, nesta seção, os resultados da análise empreendida, junto a exemplos de textos que compõem os frames identificados e que se mostram mais proveitosos para os objetivos da pesquisa. A unidade de análise é o editorial, e cada texto foi classificado em apenas um

\footnotetext{
${ }^{5}$ Não se faz uma classificação de valência neste trabalho. Embora Matthes e Kohring mencionem que a avaliação moral pode ser positiva, negativa ou neutra, interessa ao trabalho a caracterização e argumentação desenvolvida pelos textos e não classificar sua valência em relação aos agentes políticos.

${ }^{6} \mathrm{O}$ livro de códigos e os arquivos codificados estão disponíveis mediante demanda à autora.
} 
dos enquadramentos. Inicia-se com a exposição dos resultados concernentes aos editoriais da FSP.

\section{Enquadramentos da Folha de S. Paulo}

\section{Gráfico 1 - Enquadramentos identificados na cobertura de Folha de S. Paulo}

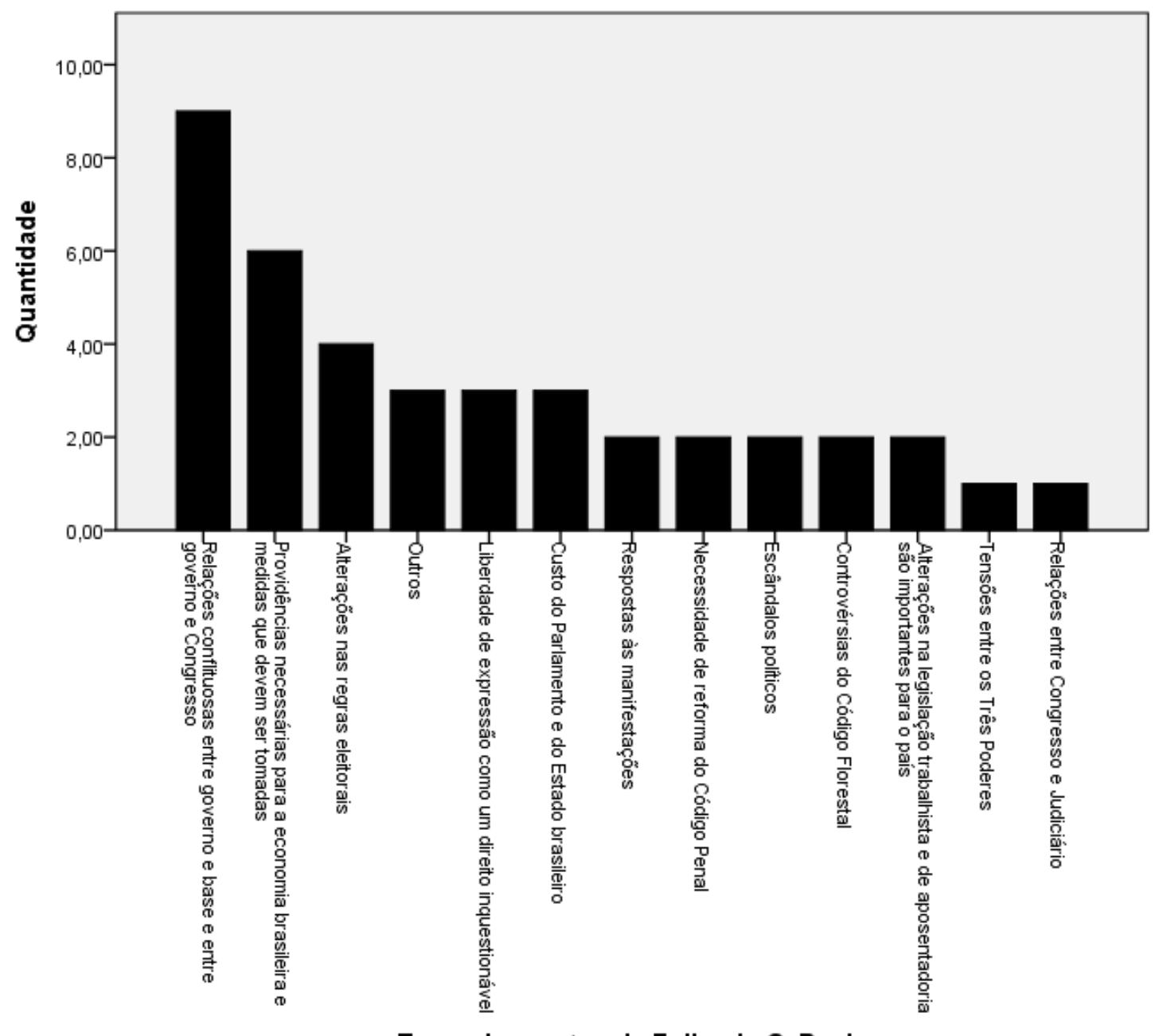

Enquadramentos da Folha de S. Paulo

Fonte: Elaboração da autora (2017).

O frame que mais se repete na cobertura da FSP é "Relações conflituosas entre governo e base aliada e entre governo e Congresso de forma geral", presente em nove editoriais (22,5\% do total de editoriais pertencentes ao jornal). Um dos textos mobilizando esse enquadramento, "Crise e acomodação", é de 17 de março de 2012. O periódico acredita que a crise da qual se fala à época está ligada às disputas de poder entre os partidos. 
Generalizou-se o nome de "crise" para uma confluência de conflitos políticos que, apesar da algazarra parlamentar, parecem circunscritos ao comércio de postos de poder-mercado de onde não devem transbordar, dada a tranquilidade social e econômica no país. São contendas que derivam do gradual rearranjo do governo de Dilma Rousseff, assim como das disputas de poder entre partidos, em especial PMDB e PT, e também intrapartidárias (Folha de S. Paulo, 17 mar. 2012, p. A2).

Para o jornal, a crise política não passa de uma disputa por cargos, o que diminui seu tamanho e faz com que tenha de ser resolvida pelos envolvidos. O problema seria, porém, que questões enumeradas pelo periódico como pertencentes ao interesse geral ficam paralisadas.

O clima conflituoso paralisa o Congresso, sem dúvida, e obsta a resolução de disputas de interesse mais geral. Entre outras, o Código Florestal, o fundo de pensão dos servidores e a lei do petróleo. O cordão sanitário da estabilidade na maior parte do país por si só tenderia a barrar transbordamentos desses embates além da praça dos Três Poderes. O fato de que tal conflito se limite a cargos e favores é outro diminutivo da crise (Folha de S. Paulo, 17 mar. 2012, p. A2).

Em seguida, "Providências necessárias para a economia brasileira e medidas que devem ser tomadas" aparece em seis editoriais da FSP (15\%). Neste frame, incentivos fiscais são tema do editorial "A arte da guerra", de 4 de maio de 2013. O jornal aborda a reforma no ICMS, cujo trâmite teria sido apressado devido à possibilidade de um "apagão legal”, pois as manobras com o imposto estavam sendo invalidadas pelo Supremo Tribunal Federal (STF). O cerne da proposta apresentada pelo governo ao Congresso seria "retirar dos Estados o poder de conceder benefícios com o tributo". A FSP acredita, porém, que a proposta está sob ameaça, o que pode manter ou agravar o regime de taxas permitindo a chamada "guerra fiscal".

O frame "Alterações nas regras eleitorais" está presente em quatro editoriais (10\%). Um dos textos mobilizando o enquadramento é "Voto distrital", de 23 de fevereiro de 2011, no qual a FSP defende a adoção do voto distrital misto para eleições proporcionais. O jornal menciona diversos exemplos de desvios ocorridos em Legislativos de todos os níveis da 
Federação e credita o sistema político como um dos culpados. Para a publicação, o voto distrital misto permitiria criar “(...) um mecanismo fiscalizador mais eficiente sobre a atuação do legislador, seus eleitores no distrito e os adversários que anseiam por substituílo" (Folha de S. Paulo, 23 fev. 2011, p. A2). O jornal percebe que a reforma política está na agenda de preocupações e busca pressionar pela medida que julga mais proveitosa. "A reforma política parece ser uma das prioridades do novo governo no Congresso. É a oportunidade para discutir o aperfeiçoamento das regras para eleições legislativas no país. Não há razão para excluir o modelo distrital misto dos debates" (Folha de S. Paulo, 23 fev. 2011, p. A2).

Os enquadramentos "Custo do Parlamento e do Estado brasileiro"; "Liberdade de expressão como um direito inquestionável" e; "Outros" estão presentes em três editoriais cada um (7,5\%). O editorial "Senado além da conta", de 8 de maio de 2013, aciona o primeiro e aborda gastos considerados desnecessários da Casa. Para o periódico, isso é sinal do pouco compromisso do então Presidente do Senado, Renan Calheiros, com a redução das despesas.

Vê-se que não vai longe a propalada disposição de Renan Calheiros (PMDBAL) para reduzir as despesas da Casa. Eleito presidente do Senado sob protesto da opinião pública, ele anunciou cortes anuais de R\$262 milhões (num orçamento de $\mathrm{R}$ \$ 3,4 bilhões). Mas a tesoura preservou os congressistas (Folha de S. Paulo, 8 mai. 2013, p. A2).

O periódico lista as regalias aos senadores que foram mantidas, mesmo com os cortes, afirmando que há uma "atmosfera de descaso com a coisa pública", cobrando que "Alguém precisa assumir a culpa por tamanha prodigalidade" (Folha de S. Paulo, 8 mai. 2013, p. A2).

O enquadramento "Liberdade de expressão como um direito inquestionável" é o único em que se registra avaliação positiva aos congressistas. Em "Biografias em risco", de 11 de fevereiro de 2011, o periódico trata do projeto de lei permitindo a publicação de biografias de pessoas de notoriedade pública sem a autorização delas ou de seus familiares. A FSP considera "elogiável" a iniciativa do ministro da Justiça, José Eduardo Cardozo, de alterar 
a legislação vigente na época. O periódico argumenta que a proibição de publicar livros não é compatível com o regime democrático.

Cinco frames aparecem em dois textos cada. São eles: "Alterações na legislação trabalhista e de aposentadoria são importantes para o país"; "Necessidade de reforma do Código Penal"; "Escândalos políticos"; "Controvérsias do Código Florestal" e; "Respostas às manifestações" (5\%). Por fim, os frames "Tensões entre os Três Poderes" e "Relações entre Congresso e Judiciário" figuram em um texto cada $(2,5 \%)$.

Os textos pertencentes ao enquadramento "Escândalos políticos" tratam do escândalo envolvendo o então senador Demóstenes Torres. É o caso de "Oposição na míngua", de 30 de março de 2012. A FSP recorda a trajetória do ex-senador, que tinha papel importante como oposição ao governo. O jornal ainda critica a oposição brasileira, que faria o inverso do esperado, a saber: vigiar o poder e constituir uma alternativa ao governo vigente.

\footnotetext{
Parte da oposição brasileira segue no rumo inverso: muitos de seus integrantes migram para o terreno fértil do governismo, outros se paralisam diante do sucesso das políticas sociais petistas, enquanto outros mais se envolvem em escândalos que minam sua autoridade para fiscalizar os feitos e malfeitos da situação (Folha de S. Paulo, 30 mar. 2012, p. A2)
}

Em um dos editoriais que mobiliza o frame "Controvérsias do Código Florestal", "Sobre leis e florestas", o jornal repercute a aprovação do Código Florestal, que teria escassa chance de ser efetivo, de acordo com sua avaliação. O Código aprovado pela Câmara também teria consequências para o jogo político, mas o periódico aponta que sua importância transcende as disputas partidárias. Na visão do jornal, o novo Código Florestal "nasce velho e relega a proteção do ambiente brasileiro" (Folha de S. Paulo 28 abr. 2012, p. A2).

O editorial "Brasília se agita", de 27 de junho de 2013, aciona o enquadramento "Respostas às manifestações" e aborda as respostas de diversas instituições às manifestações daquele mês. O periódico demonstra surpresa com as reações do Congresso Nacional. "Foi o Congresso Nacional, no entanto, que se excedeu na repentina demonstração de apreço pela 
opinião pública. Como o Legislativo tem sido o Poder mais refratário a ela, fica patente o quanto Brasília tremeu diante dos protestos" (Folha de S. Paulo, 27 jun. 2013, p. A2). Para a FSP, isso fica demonstrado nos resultados da votação da PEC 37 e na aprovação de projetos como a destinação de $75 \%$ das receitas do petróleo para a educação. Todavia, nem só de iniciativas positivas seriam compostas as ações do Congresso e do Executivo. A interpretação do jornal é de que falta uma direção para as ações dos agentes políticos. "Os políticos foram tirados da inércia. Precisam, como se vê, encontrar o rumo certo" (Folha de S. Paulo, 27 jun. 2013, p. A2).

\section{Enquadramentos de O Estado de S. Paulo}

Gráfico 2 - Enquadramentos identificados na cobertura de O Estado de S. Paulo

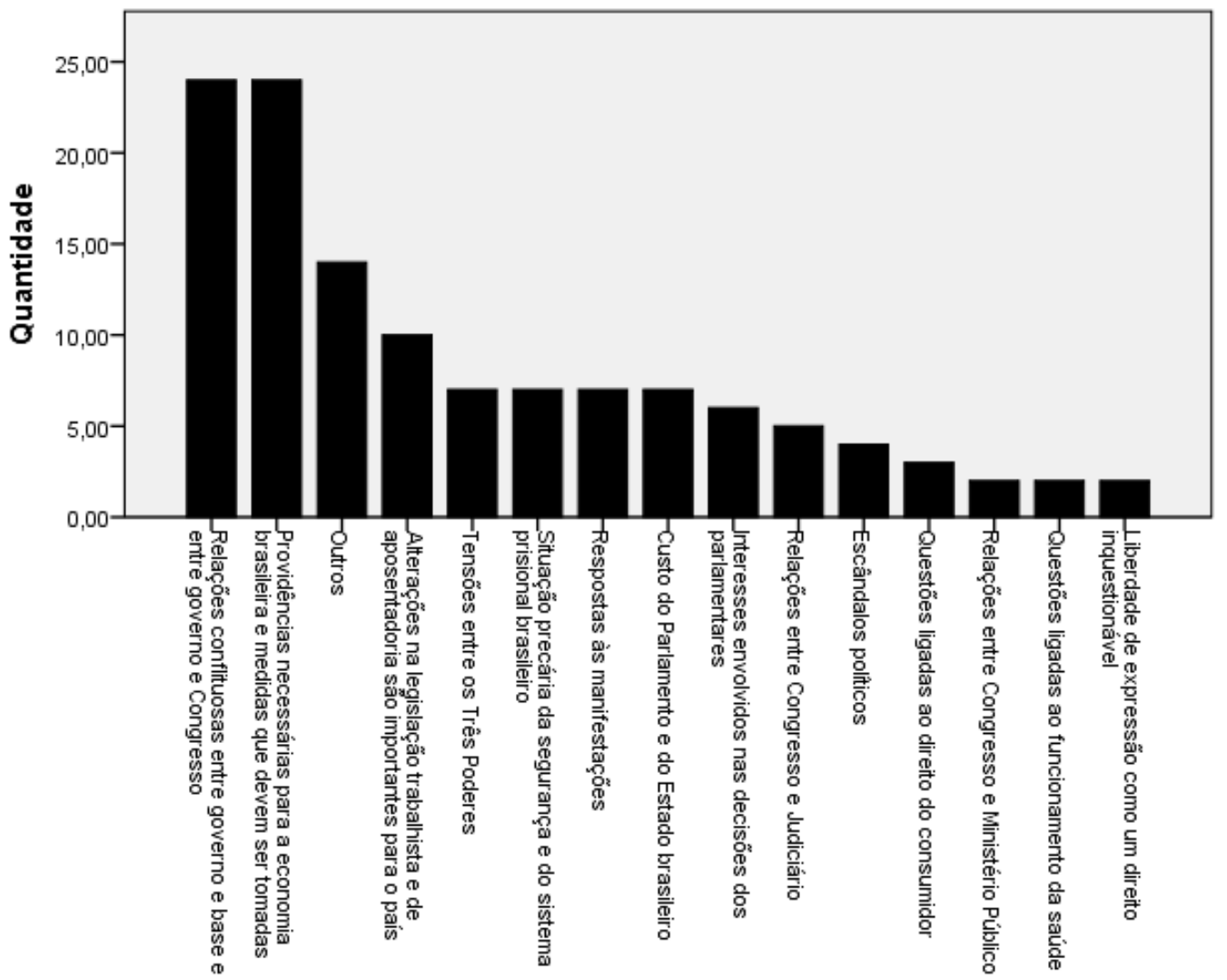

Enquadramentos de O Estado de S. Paulo

Fonte: Elaboração da autora (2017). 
No caso de OESP, os frames mais frequentes, presentes em 24 editoriais cada um, são "Relações conflituosas entre governo e base aliada e entre governo e Congresso de forma geral"; e "Providências necessárias para a economia brasileira e medidas que devem ser tomadas" (aproximadamente 19\% do total de editoriais publicados pelo jornal). O editorial “Não pode dar certo", de 26 de maio de 2013, critica a coalizão de sustentação ao governo Dilma no Congresso, acionando o primeiro enquadramento.

\footnotetext{
Porque se sustenta apenas sobre o terreno cediço das conveniências do varejo político, a mastodôntica base de apoio governista no Congresso Nacional vive criando problemas para o Palácio do Planalto, com demonstrações reiteradas de que o "presidencialismo de coalizão" de que o lulopetismo tanto se orgulha acabou criando um aparentemente admirável, mas, na verdade, frágil gigante com pés de barro (O Estado de S. Paulo, 26 mai. 2013, p. A3).
}

O periódico não se apresenta necessariamente contra a existência de uma base parlamentar sólida nas democracias, considerando-a como indispensável para a estabilidade de regimes democráticos. O problema apontado, no caso brasileiro, seria o motivo pelo qual as alianças são formadas, criticando a ausência de alinhamento ideológico entre governo e base. “(...) alianças políticas, mesmo não dispensando um inevitável quinhão de fisiologismo, devem ser construídas sobre bases mais consistentes do que o mero toma lá dá cá" (O Estado de S. Paulo, 26 mai. 2013, p. A3). Para a publicação, a governabilidade estaria se esvaindo, enquanto o PMDB apresentava requerimento para criação de uma CPI na Câmara dos Deputados para investigar irregularidades na Petrobras. Embora defenda que a empresa deve ser investigada, OESP não acredita que saia algum resultado da proposta de CPI. Ela seria, antes, uma ferramenta para a base pressionar o governo.

Um exemplo de editorial com o frame "Providências necessárias para a economia brasileira e medidas que devem ser tomadas" é "A importante pauta da CNI", publicado em 29 de março de 2012, tratando do lançamento da Agenda Legislativa da Indústria, que deveria ser levada em conta pelos parlamentares. "Interessa a todo o País, por sua importância para a produção, a criação de empregos e o desenvolvimento, a agenda levada ao Congresso pelo presidente da Confederação Nacional da Indústria (CNI) (...)” (O Estado de S. Paulo, 29 mar. 2012, p. A3). 
O jornal reconhece que os objetivos do empresariado podem diferir daqueles de interesse da sociedade, mas que a pauta apresentada nestes momentos costuma tocar em medidas necessárias para o crescimento econômico e para a redução da pobreza. O periódico atribui, ainda, a longa tramitação ou o esquecimento de projetos importantes ao fato de que "O sentido de urgência dos parlamentares muito raramente coincide com o dos empresários ou, de modo geral, com o dos cidadãos interessados na solução de questões fundamentais para a segurança, o bem-estar e a prosperidade de quem vive no Brasil real" (O Estado de S. Paulo, 29 mar. 2012, p. A3).

Quatorze textos foram agrupados em "Outros" (11\%), reunindo editoriais sem um enquadramento específico. Dez peças têm como frame "Alterações na legislação trabalhista e de aposentadoria são importantes para o país” (8\%). Quatro enquadramentos foram encontrados em sete textos cada (5,6\%). São eles: "Custo do Parlamento e do Estado brasileiro"; "Situação precária da segurança e do sistema prisional brasileiro"; "Tensões entre os Três Poderes" e "Respostas às manifestações".

O editorial "A privatização do Senado", de 13 de março de 2012, aborda os gastos com funcionários da Casa, mobilizando o enquadramento "Custo do Parlamento e do Estado brasileiro". OESP critica a quantidade funcionários comissionados do Senado, assim como afirma que "Senadores continuam fiéis às tradições de empreguismo e de uso de recursos públicos para fins privados, marcas bem conhecidas da vida parlamentar brasileira" (O Estado de S. Paulo, 13 mar. 2012, p. A3). OESP propõe uma separação rigorosa entre o público e o privado, sem acreditar que isso pode ser feito pelo Senado. "Qualquer esforço para tornar a política brasileira mais "republicana" (um adjetivo muito em moda) só dará certo se envolver um sério trabalho de separação do público e do particular. O Parlamento, hoje, não parece o lugar mais propício para se iniciar essa tarefa" (O Estado de S. Paulo, 13 mar. 2012, p. A3).

Um dos editoriais trazendo o enquadramento "Tensões entre os Três Poderes" é "Falas irresponsáveis", de 23 de maio de 2013. Neles, são criticadas declarações do então Presidente do STF, Joaquim Barbosa, e da então ministra Maria do Rosário, que chefiava a Secretaria dos Direitos Humanos. O jornal admite que a avaliação de Barbosa do 
Congresso aproxima-se do que os cidadãos pensam da instituição e que traz prováveis verdades, mas julga-a irresponsável.

O presidente do Supremo Tribunal Federal (STF), ministro Joaquim Barbosa, endossou o que a grande maioria dos brasileiros acha do Congresso Nacional e dos partidos políticos. O Congresso, disse ele segunda-feira em palestra na faculdade onde leciona, em Brasília, é ineficiente e inteiramente dominado pelo Poder Executivo (O Estado de S. Paulo, 23 mai. 2013, p. A3).

Para OESP, o chefe de um Poder não pode dizer em público o que pensa de instituições que formam os outros Poderes, independentemente do fundamento da avaliação. $O$ periódico critica a justificativa do ministro de que falara como acadêmico, sem juízos de valor e a fala seria apenas um exercício intelectual, pois não enxerga dissociação entre o ministro e o acadêmico.

O editorial "Para a rua ver", do dia 25 de junho de 2013, mobiliza o enquadramento "Respostas às manifestações". Assim como a FSP, OESP diagnostica que as instituições tentam dar respostas aos manifestantes, mas critica as propostas apresentadas. O jornal desconfia da proposta de reforma política, avaliando que ela não é solução para os problemas da democracia brasileira.

\begin{abstract}
A rua também pode achar que a reforma política é a panaceia para a corrupção, e o desdém dos eleitos pelos eleitores. Não é. Pode tornar o sistema mais representativo ou mais produtivo e, no melhor dos mundos, mais atento à vontade geral, e não apenas aos seus patrocinadores, clientelas e grupos de pressão. No Congresso, os messiânicos da reforma parecem ignorar que, em última análise, não é mudando as regras do ofício que os políticos se tornarão automaticamente avessos à corrupção, abandonando práticas entranhadas $(\mathrm{O}$ Estado de S. Paulo, 25 jun. 2013, p. A3)
\end{abstract}

"Interesses envolvidos nas decisões dos parlamentares" está presente em seis editoriais $(4,8 \%)$, enquanto "Relações entre o Congresso e o Judiciário" aparece em cinco (4\%). O editorial "Os males das coligações", de 8 de fevereiro de 2011, mobiliza o primeiro enquadramento, enquanto defende o fim das coligações para eleições proporcionais. OESP (8 fev. 2011, p. A3) avalia que o sistema de coligações causa a "proliferação de legendas 
nanicas", mas também é responsável por "algo ainda pior: o efeito perverso de distorcer a vontade do eleitor (...)". O periódico atribui a persistência do modelo à sua conveniência para os agentes políticos.

\begin{abstract}
Naturalmente, como tudo mais nas regras da competição política, o arranjo sobrevive porque convém aos competidores. Todo o resto sendo igual, as chances de um interessado em "servir ao povo" são maiores à sombra de uma coligação do que em raia partidária exclusiva (O Estado de S. Paulo, 8 fev. 2011, p. A3).
\end{abstract}

Quatro textos trazem o frame "Escândalos políticos" (3\%). Assim como no caso da FSP, o foco dos editoriais mobilizando tal enquadramento consiste no escândalo envolvendo o então senador Demóstenes Torres, porém a OESP trata também de outros agentes políticos. É o que acontece em "Diferentes, porém iguais", de 28 de março de 2012. O Estado de S. Paulo (28 mar. 2012, p. A3) afirma que o caso de Demóstenes “[...] é mais um que se inscreve na galeria dos recentes atentados à ética na vida pública. [...] o senador democrata já está em débito com as práticas saudáveis da política republicana". O jornal menciona também o caso de Fernando Pimentel, acusado de aproveitar-se de sua proximidade com Dilma Rousseff para se beneficiar de contratos feitos com a Federação das Indústrias de Minas Gerais. O periódico se coloca em posição de cobrar investigações e punições aos dois personagens, assim como avalia que os casos evidenciam os problemas éticos permeando a política brasileira.

Três editoriais tratam de "Questões relacionadas ao Direito do Consumidor" $(2,4 \%)$. Por fim, três enquadramentos estão presentes em dois textos cada: "Questões ligadas ao funcionamento da saúde"; "Liberdade de expressão como um direito inquestionável" e "Relações entre Congresso e Ministério Público" (1,6\%). 


\section{Discussão e considerações finais}

A análise dos editoriais apresentada na seção anterior revela uma imagem pública predominantemente negativa do Congresso Nacional. A caracterização da instituição feita por OESP e FSP é semelhante à identificada por Rozell (1994, p. 110) na cobertura do Jornalismo americano sobre o Congresso dos EUA. "A imprensa retrata os legisladores da nação como políticos autointeressados, autoindulgentes, que exploram o processo legislativo para seu próprio benefício."

A cobertura envolvendo o Congresso Nacional, de acordo com os editoriais analisados, segue uma tendência já identificada na literatura, focando nos conflitos entre os diversos agentes políticos, assim como nas ambições dos congressistas e nos motivos pelos quais tomam certas decisões (ARNOLD, 2004; ERIKSSON; OSTMAN, 2013; FALLOWS, 1997; GOMES, 2004; MIGUEL, 2014; SCHUDSON, 2008). Em alguns editoriais, porém, como os que mobilizam frames a exemplo de "Situação precária da segurança e do sistema prisional brasileiro", questões substanciais são debatidas pelos periódicos, contrariando a literatura (não obstante a disputa política aparecer como plano de fundo em alguns deles).

OESP e FSP auxiliam a construir negativamente a imagem do Congresso e dos parlamentares, ao afirmar que há descaso com o dinheiro público ou que suas decisões são estritamente ligadas a interesses eleitorais. Entretanto, pelo menos nos editoriais que compõem o corpus, a imagem negativa não é exclusividade dos parlamentares. O governo também é caracterizado a partir de perspectivas que não ressaltam atributos positivos muitas vezes, cedendo às chantagens dos congressistas aliados ou aproveitando-se das vantagens de utilizar a máquina pública para facilitar a tramitação de assuntos de seu interesse. Algumas instituições e agentes do Judiciário também são criticados nos editoriais, o que pode indicar uma desconfiança em relação às instituições de maneira geral.

Ao mesmo tempo, os periódicos prezam pelos fundamentos do regime democrático - ou aparentam fazê-lo. No caso de OESP, a separação entre os Poderes e o fato de encararem o Parlamento como espaço da representação popular são especialmente importantes. A FSP também demonstra preocupação com a manutenção e com o respeito às regras da 
democracia. Neste sentido, os resultados encontrados aqui diferem do que é defendido por Porto (apud NOVELLI, 2010), de que a cobertura não faz uma distinção entre os integrantes do Congresso Nacional e da importância da instituição para o regime democrático.

Considerar a importância do Legislativo para a democracia, porém, não livra os jornais de incidirem em simplificações, ao referirem-se a Congresso como uma instituição homogênea, desconsiderando as diferenças entre as Casas (AZEVEDO, 2005), exceto quando tratam dos gastos do Senado. A ausência das distinções entre as Casas, na maioria dos editoriais, corrobora a ideia de Cook (1989) de que a cobertura tende a simplificar os assuntos. Isso pode ser especialmente prejudicial quando se trata de questões políticas, por dar a ideia de que os problemas podem ser resolvidos pela simples disposição dos agentes políticos em fazê-lo, desconsiderando a complexidade do processo legislativo ou das decisões governamentais.

Os dois enquadramentos mais frequentemente acionados - "Relações conflituosas entre governo e base e entre governo e Congresso de forma geral" e "Providências necessárias para a economia brasileira e medidas que devem ser tomadas" - repetem-se tanto em FSP quanto em OESP, indicando alguma sintonia quanto à maneira de tratar o Congresso Nacional. Mais que isso, eles apontam preocupações com questões distintas (e, possivelmente, encaradas como prioritárias pelos periódicos): a) as relações entre o governo e Congresso b) a adoção de medidas para incrementar a economia brasileira, especialmente, no caso de OESP.

O fato de tanto FSP quanto OESP terem mais editoriais abordando o Congresso Nacional a partir de suas relações com o Executivo indica o que entendem e, consequentemente, legitimam como política. O argumento recorrente no frame "Relações conflituosas entre governo e base e entre governo e Congresso de forma geral" é o de que a relação entre o governo e a sua base aliada no Congresso é pautada por relações "fisiológicas", nas quais seria necessário que o Executivo concedesse as benesses exigidas pelos parlamentares para ver os projetos de seu interesse aprovados. OESP, especificamente, chega a se opor a medidas com as quais simpatiza, a exemplo da instituição do orçamento impositivo, devido aos interesses dos parlamentares na sua aprovação. 
Vários editoriais tratam a aprovação de medidas de interesse do governo a partir de uma perspectiva de vitória ou derrota imposta pela base aliada, encarando a política como uma competição, com vencedores e perdedores, algo criticado pela literatura (FALLOWS, 1997; KOVACH; ROSENSTIEL, 2004). Os dois jornais tratam da importância de compensações para o suporte oferecido pela base ao governo, configurando a ideia de que o Congresso não trabalha sem ganhar benefícios em troca - e que o compromisso dos agentes políticos não é com a sociedade.

Em editoriais mobilizando o enquadramento é "Providências necessárias para a economia brasileira e medidas que devem ser tomadas", mencionam-se as dificuldades criadas pelo jogo político e pelo Congresso para a aprovação de medidas saneadoras dos gastos públicos. O apoio dos parlamentares às reduções de gastos seria condicionado ao fato de resguardarem seus interesses, como as emendas parlamentares. Caso isso não ocorresse, poderiam retirar tal suporte. O Congresso é retratado como ameaça aos esforços do governo para manter os gastos sob controle.

OESP também sugere a adoção da pauta da Confederação Nacional da Indústria (CNI) como norteadora das ações de Congresso e do governo. Se o Executivo e o Legislativo estão sob constante suspeição por parte da cobertura, o setor empresarial dispõe de crédito suficiente para o periódico cobrar que sua agenda seja observada pelos agentes políticos. Os compromissos do periódico podem ser responsáveis pela importância conferida à pauta da CNI, que contempla a da própria publicação, e procura enquadrar a agenda da indústria como aquela que atende aos interesses da população, em oposição à agenda do campo político.

Em grande parte dos editoriais sobre medidas econômicas que passariam pelo Congresso, a posição cobrada dos parlamentares é de aprovar as medidas que seriam de interesse do país - e que são apontadas pelos periódicos. Em diversas peças, FSP e OESP se dedicam a criticar a política econômica do governo, prescrevendo medidas que deveriam ser tomadas para melhorá-la.

O questionamento dos gastos de instituições legislativas - do Senado, em especial - é a principal pauta dos editoriais que possuem elementos do frame "Custo do parlamento e do 
Estado brasileiro". Chama a atenção que os gastos específicos da Câmara dos Deputados não são questionados pelos periódicos, ao contrário do que acontece com o Senado. FSP e OESP não conferem crédito às promessas de redução de gastos dos presidentes do Senado. Os parlamentares seriam, portanto, desprovidos de preocupação com o gasto público, procurando usufruir das regalias oferecidas pelo cargo sem reduzi-las, além de demonstrarem interesse superficial por discutir o saneamento dos gastos da Casa, que seria aventado apenas para preservar as próprias imagens públicas.

Nos editoriais tratando do frame "Tensões entre os Três Poderes", os conflitos entre Legislativo, Executivo e Judiciário costumam estar presentes. O terceiro, porém, é retratado, em parte dos casos, como responsável por resolver problemas criados pelos outros dois. Porém, a intervenção do Judiciário nos assuntos políticos nem sempre é bem vista. Nota-se que OESP, principalmente, tenta se posicionar como árbitro do conflito entre os Poderes.

A situação é um exemplo de como o Jornalismo busca atuar como uma espécie de Poder Moderador (ALBUQUERQUE, 2000), posicionando-se como um protetor da ordem e procurando arbitrar os conflitos entre as diferentes esferas de poder, como se este papel naturalmente coubesse às instituições jornalísticas. As empresas parecem atribuir-se "um papel metapolítico, de principal intérprete do interesse nacional, por cima das instituições políticas representativas" (ALBUQUERQUE; HOLZBACH, 2008, p. 169), de modo que "pairam" sobre outras instituições do país, apontando problemas e soluções.

Nos editoriais com o enquadramento "Respostas às manifestações", é possível encontrar diferenças mais significativas sobre como os periódicos avaliam certas medidas. OESP critica a aprovação da PEC 37 por causa da pressão dos manifestantes, enquanto a FSP vê a medida de forma positiva, considerando-a uma vitória dos protestos. Ambos concordam que as instituições foram surpreendidas pelas manifestações e, por isso, procuram mostrarse dispostas a atender as reivindicações, embora desconfiem dos resultados que podem sair das decisões.

OESP não se posiciona abertamente contra os protestos, mas afirma que o espaço legítimo para a representação da população é o Parlamento, criticando boa parte das medidas 
tomadas pelas instituições para tentar contemplar a população. A FSP também discorda de parte das ações propostas pelo governo e pelo Congresso e oferece sugestões. Os jornais se mostram surpresos, nos editoriais, com as reações causadas pelas manifestações no Congresso, considerada, pelas publicações, uma das instituições mais refratárias à participação popular.

A compreensão dos jornais sobre os valores democráticos prioritários a serem resguardados, naquele momento, parecem entrar em conflito. Enquanto a FSP vê a participação popular como fundamental para o processo, OESP restringe o que reconhece como participação, considerando o voto como o momento mais propício para manifestação dos cidadãos - ainda que evite deslegitimar os protestos.

Alguns frames não se repetem nos dois jornais. Isso pode acontecer pelas próprias diferenças nas publicações, que julgam alguns aspectos mais importantes que outros. Um exemplo é que, em OESP, o Código Florestal não recebeu o mesmo destaque atribuído pela FSP à legislação. Enquanto o segundo publicou alguns editoriais se opondo à aprovação do código com vantagens para os ruralistas, OESP julga ser uma legislação equilibrada, sem dedicar muito espaço para debatê-la.

Apenas OESP traz o enquadramento "Interesses envolvidos nas decisões dos parlamentares". Os editoriais desta seção reforçam a imagem de congressistas que procuram apenas tirar o máximo de vantagens das diversas relações que têm, sem preocupação com o gasto público. Para o periódico, os parlamentares colocam os interesses acima das medidas em benefício do país, como o corte de gastos.

Um aspecto que chama atenção se refere à avaliação sobre a base aliada e a oposição: embora a primeira tenda a ser retratada como a maior participante das barganhas, a caracterização negativa não se restringe aos seus integrantes. Em relação à aprovação de medidas como o aumento do Fundo Partidário, a manutenção das coligações proporcionais ou a liberação de candidatos que tiveram as contas reprovadas, OESP avalia que elas acontecem porque beneficiam os parlamentares, sem fazer distinção. De acordo com os editoriais trazendo o frame mencionado acima, os parlamentares seriam movidos pela possibilidade de lucrarem com as medidas que estiverem em pauta, sem importar as 
consequências das decisões. O jornal estabelece uma oposição entre campo político e sociedade, sem distinções entre os agentes do primeiro.

Ao considerar trabalhos lidando com outros contextos (ASHER; BARR, 1994; COOK, 2005; NEGRINE, 1999; ROZELL, 1994), percebe-se que, apesar de certas diferenças, a cobertura de OESP e de FSP sobre o Congresso brasileiro segue um padrão semelhante à cobertura feita pelo Jornalismo americano, com uma tendência a desconfiar das instituições e de seus integrantes. Mais que uma escolha deliberada do campo jornalístico, portanto, uma cobertura crítica está ligada às próprias rotinas da profissão, assim como ao papel social que o Jornalismo se atribui - pelo menos, aquele inspirado no modelo americano.

Todavia, vale observar que, embora o Jornalismo retrate o Congresso Nacional a partir de uma perspectiva negativa, não há questionamento sistemático acerca das limitações da democracia representativa. Problemas inerentes à representação política, como o distanciamento entre representantes e representados ou a ruptura do vínculo entre a vontade dos dois (MIGUEL, 2014) raramente são mencionados. A construção de imagem negativa do Congresso esconde, de certa maneira, a discussão sobre questões estruturais da democracia.

Os periódicos ainda estabelecem momentos nos quais o campo político deve seguir as instruções oferecidas - deslocando a discussão econômica da esfera política - e outros nos quais compreendem os agentes políticos como atores autônomos e em busca dos próprios interesses - e, por consequência, seria necessário que estivessem sujeitos a forte escrutínio, um papel que as empresas procuram se legitimar para cumprir.

Por fim, ressalte-se que, embora alguns enquadramentos mobilizados pelos periódicos sejam repetidos, há diferenças entre as prioridades de cada uma das empresas (algumas vezes, suas agendas são até conflitantes). Isso demonstra que a atuação delas não pode ser encarada como a atuação em um bloco homogêneo, indicando a complexidade do papel desempenhado pelo campo jornalístico brasileiro. 


\section{Notas}

1 "Rebeldia e desalento" é o título de um dos editoriais compondo o corpus deste artigo, publicado pela FSP em 23 de março de 2012.

\section{Referências}

AALBERG, T.; STRÖMBÄCK, J.; DE VREESE, C. H. The framing of politics as strategy and game: A review of concepts, operationalizations and key findings. Journalism, v. 13, n. 2, p. 162-178, 1 fev. 2012.

ALBRIGHT, S. Opinion readership scores higher than common wisdom predicts. The Masthead, v. 47, n. 1, p. 5, 1995.

ALBUQUERQUE, A. DE. Um outro quarto poder: jornalismo e responsabilidade política no Brasil. Contracampo, v. 4, p. 23-57, 2000.

ALBUQUERQUE, A. DE; HOLZBACH, A. D. Metamorfoses do contrato representativo: jornalismo, democracia e os manuais da redação da Folha de S. Paulo. comunicação, mídia e consumo, v. 5, n. 14, p. 149-170, 2008.

ALDIGHIRNI, Z. Jornalismo e poder legislativo: relações entre mídia e política no Brasil. Curitiba: APPRIS, 2015.

ARMAÑANZAS, E.; NOCÍ, J. D. Periodismo y argumentación. Géneros de opinión. [s.I.] Universidad del País Vasco, 1996.

ARNOLD, R. D. Congress, the Press, and Political Accountability. Princeton: Princeton University Press, 2004.

ASHER, H.; BARR, M. Popular support for Congress and its members. In: MANN, T. E.; ORNSTEIN, N. J. (Eds.). . Congress, the Press, and the Public. Washington: Brookings Institution, 1994. p. 15-43.

AZEVEDO, F. A Grande Imprensa Brasileira: Paralelismo Político e Antipetismo (1989-2014). [s.I.] Universidade Federal de São Carlos, 2016.

Imprensa e Legislativo: os editoriais da Folha de S. Paulo sobre o Senado (20032004). 2005. Disponível em: <http://www.compos.org.br/data/biblioteca_793.pdf>. Acesso em: 17 mai. 2017.

Mídia e democracia no Brasil: relações entre o sistema de mídia e o sistema político. Opinião Pública, v. 12, n. 1, p. 88-113, 2006.

; CHAIA, V. O Senado nos editoriais dos jornais paulistas (2003-2004). Opinião Pública, v. 14, n. 1, p. 173-204, 2008.

BARDIN, L. Análise de conteúdo. Lisboa: Edições 70, 1977. 
BAUER, M. W. Análise de conteúdo clássica: uma revisão. In: BAUER, M. W.; GASKELL, G. (Eds.). . Pesquisa qualitativa com texto, imagem e som: um manual prático. Rio de Janeiro: Vozes, 2002. p. 189-217.

BELTRÃO, L. Jornalismo opinativo. Porto Alegre: Sulina, 1980.

BILLEAUDEAUX, A. et al. Newspaper editorials follow lead of Bush administration. Newspaper Research Journal, v. 24, n. 1, p. 166-184, 2003.

CAPELLA, J. N.; JAMIESON, K. H. Spiral of cynicism. New York: Oxford University Press, 1997.

CAVALCANTE, R. B.; CALIXTO, P.; PINHEIRO, M. M. K. Análise de conteúdo: considerações gerais, relações com a pergunta de pesquisa, possibilidades e limitações do método.

Informação \& Sociedade: Estudos, v. 24, n. 1, p. 13-18, 2014.

CHAIA, V. Imprensa e Câmara Municipal de São Paulo - 1989-1996:

www.bvshistoria.coc.fiocruz.br/lildbi/docsonline/get.php?id=205., 1999.

COOK, T. E. Making laws and making News. Washington: The Brookings Institution, 1989.

Governing with the news. Chicago: The University of Chicago Press, 2005.

EDELMAN, M. Constructing the Political Spectacle. Chicago: University of Chicago Press, 1988.

EILDERS, C. Synchronization of Issue Agendas in News and Editorials of the Prestige Press in Germany. The International Journal of Communications Research, v. 24, n. 3, p. 301-328, 1999.

ENTMAN, R. M. Framing: Toward clarification of a fractured paradigm. Journal of Communication, v. 43, n. 4, p. 51-58, 1993.

ERIKSSON, G.; OSTMAN, J. Cooperative or Adversarial? Journalists' Enactment of the Watchdog Function in Political News Production. The International Journal of Press/Politics, v. 18, n. 3, p. 304-324, 2013.

ESSARY, E. H. Speaking of Globalization: Frame Analysis and the World Society. International Journal of Comparative Sociology, v. 48, n. 6, p. 509-526, 2007.

FALASCA, K. Political news journalism: Mediatization across three news reporting contexts.

European Journal of Communication, v. 29, n. 5, p. 583-597, 2014.

FALLOWS, J. Detonando a notícia: como a mídia corrói a democracia americana. Rio de Janeiro: Civilização Brasileira, 1997.

GOMES, W. Transformações da política na era da comunicação de massa. São Paulo: Paulus, 2004. Insular, 2009.

Jornalismo, fatos e interesses: ensaios de teorias do jornalismo. Florianópolis: 
GRADIM, A. Manual de Jornalismo. Covilhã: Serviços gráficos da Universidade da Beira Interior, 2000.

HALLOCK, S. M. Editorial and Opinion. Praeger: Westport, 2007.

IZADI, F.; SAGHAYE-BIRIA, H. A discourse analysis of elite American newspaper editorials: The case of Iran's nuclear program. Journal of Communication Inquiry, v. 31, n. 2, p. 140-165, 2007.

JORGE, V. L. A Cobertura do Congresso Nacional pelos Jornais Brasileiros, 1985-1990. Estudos Históricos, n. 31, p. 64-82, 2003.

KAHN, K. F.; KENNEY, P. J. The Slant of the News: How Editorial Endorsements Influence Campaign Coverage and Citizens Views of Candidates. American Political Science Review, v. 96, n. 2, p. 381-394, 2002.

KOVACH, B.; ROSENSTIEL, T. Os elementos do jornalismo. São Paulo: Geração Editorial, 2004.

KRIPPENDORFF, K. Content Analysis: An Introduction to Its Methodology. London: Sage Publications, 2004. v. 79.

KUMAR, M. J. Managing the President's message: The White House Communications Operation. Baltimore: The Johns Hopkins University Press, 2007.

MARQUES, F. P. J.; MONT'ALVERNE, C.; MITOZO, I. O Impeachment de Dilma Rousseff nos Editoriais de Folha e Estadão: Um estudo quanti-qualitativo sobre o posicionamento político dos jornais. São Paulo: Compós, 2017.

MATTHES, J.; KOHRING, M. The Content Analysis of Media Frames: Toward Improving Reliability and Validity. Journal of Communication, v. 58, n. 2, p. 258-279, jun. 2008.

MELO, J. M. DE. A opinião no jornalismo brasileiro. Petrópolis NV - 166: Vozes, 1985.

MIGUEL, L. F. Os meios de comunicação e a prática política. Lua Nova: Revista de Cultura e Política, n. 55-56, p. 155-184, 2002. 2014.

Democracia e representação: territórios em disputa. São Paulo: Editora Unesp,

MIOLA, E. Sistema deliberativo e tensões entre interesses públicos e privados: A criação da Empresa Brasil de Comunicação em debate no Congresso e na imprensa. Belo Horizonte, Brasil: Universidade Federal de Minas Gerais, 2012.

MONT'ALVERNE, C. "Pródigo em decisões contra o interesse público": imagem pública, agendamento e enquadramento do Congresso Nacional nos editoriais dos jornais $\mathrm{O}$ Estado de S. Paulo e Folha de S. Paulo. [s.I.] Universidade Federal do Ceará, 2016.

; MARQUES, F. P. J. A. A opinião da empresa no Jornalismo brasileiro: Um estudo sobre a função e a influência política dos editoriais. Estudos em Jornalismo e Mídia, v. 12, n. 1, p. 121-137, 2015. 
MOTTA, L. G.; GUAZINA, L. S. O conflito como categoria estruturante da narrativa política: o caso do Jornal Nacional. Brazilian Journalism Research, v. 6, n. 1, 2011.

NEGRINE, R. Parliaments and the media: A changing relationship? European Journal of Communication, v. 14, n. 3, p. 325-352, 1999.

NOVELLI, A. L. C. R. Imagens Cruzadas: A opinião pública e o Congresso Nacional. Brasília: Senado Federal, 2010.

RODRIGUES, M. R. Imprensa, Congresso e democracia. [s.I.] Universidade de Brasília, 1997.

RODRIGUES, M. R. O papel da imprensa na qualidade democrática - uma análise de possibilidades nos principais jornais nacionais. [s.l.] Universidade do Estado do Rio de Janeiro, 2011.

ROZELL, M. J. Press coverage of Congress. In: MANN, T. E.; ORNSTEIN, N. J. (Eds.). .

Congress, the Press, and the Public. Washington: Brookings Institution, 1994. p. 59-129.

RUPAR, V. Newspapers' production of common sense: The "greenie madness" or why should we read editorials? Journalism, v. 8, n. 5, p. 591-610, 2007.

SCHUDSON, M. Why democracies need an unlovable press. Cambridge: Polity Press, 2008.

STRÖMBÄCK, J.; NORD, L. W. Do Politicians Lead the Tango? A study of the relationship between Swedish journalists and their political sources in the context of election campaigns.

European Journal of Communication, v. 21, n. 2, p. 147-164, 2006.

VAN AELST, P. et al. The fourth estate as superpower? Journalism Studies, v. 9, n. 4, p. 494$511,2008$.

\section{A autora}

Camila Mont'alverne é doutoranda em Ciência Política pela Universidade Federal do Paraná (UFPR) e integrante do Grupo de Pesquisa em Comunicação, Política e Tecnologia (PONTE). Bolsista Capes. camilapessoa31@gmail.com 